\title{
“Alpha Plus": An Innovative Training Program for Reading and Writing Education of Functionally Illiterate Adults
}

\author{
Jascha Rüsseler $^{1,2}$, Klaus Menkhaus ${ }^{3}$, Annegret Aulbert-Siepelmeyer ${ }^{3}$, \\ Ivonne Gerth ${ }^{4}$, Melanie Boltzmann ${ }^{4}$ \\ ${ }^{1}$ Department of Psychology, Otto-Friedrich-University Bamberg, Bamberg, Germany \\ ${ }^{2}$ Center for Behavioral and Brain Sciences (CBBS), Otto-von-Guericke University Magdeburg, \\ Magdeburg, Germany \\ ${ }^{3}$ Bildungswerk der Niedersächsischen Wirtschaft, Osnabrück, Germany \\ ${ }^{4}$ Department of Psychology, Otto-von-Guericke University Magdeburg, Magdeburg, Germany \\ Email: Jascha.Ruesseler@uni-bamberg.de
}

Received March $1^{\text {st }}$, 2012; revised April 3 ${ }^{\text {rd }}$, 2012; accepted April 26 $6^{\text {th }}, 2012$

\begin{abstract}
We describe and evaluate the effectiveness of a reading and writing training program for German functionally illiterate adults. The program "AlphaPlus" consists of the following modules: 1) training of basic perceptual abilities with the BrainBoy ${ }^{\circledR}$ /Audio-Trainer AT-3000; 2) training of brain-hemisphere coordination in the processing of spoken and written language ("Lateraltrainer"); 3) training of phoneme discrimination ("Lautdiskriminationstrainer"); 4) training of reading and writing skills with pen and paperbased material; 5) use of the learning portal www.ich-will-lernen.de developed by the German Volkshochschulverband (VHS); 6) social activities such as cooking, shopping etc.; 7) three weeks internship at possible employers. The effectiveness of the training was investigated in two courses of 18 participants each. Reading and spelling abilities of the participants improved significantly. Thus, it can be concluded that the program is effective in teaching reading and spelling to functionally illiterate adults. Further research is needed to evaluate the respective contribution of the different modules to the observed gains in reading and spelling abilities.
\end{abstract}

Keywords: Functional Illiteracy; Adults; Reading and Writing; Training Program; Evaluation

\section{Introduction}

Low-literate adolescents or adults who attended school but who, for a variety of reasons, either did not complete their education or else did complete it without attaining the expected level of reading skill are referred to as functional illiterates. Functional illiteracy is present if the level of literacy of a person is not adequate for fully effective participation in society (Baydar, Brooks-Gunn, \& Furstenberg, 1993; Eme, 2011; Kirsch et al., 1993). Thus, it corresponds to a failure to acquire functional reading skills, i.e. it describes individuals who have been taught to read and write at school but either subsequently lost this ability for reasons other than medical or who inadequately acquired reading and writing competencies in the first place (Eme, 2010). For example, a person may be able to fill in her personal details on a form or to consult the TV listings, but display poor comprehension and use of printed information in daily life at home, at work and in the community (writing out a cheque; reading a letter; addressing an envelope; reading a patient information leaflet; helping a primary school child with easy written language tasks etc.). Functional illiteracy is contrasted with illiteracy in the strictest sense, i.e. the inability to read and write at all in any language of individuals who have never attended school and have never been taught to read and write (Reis, Guerreiro, \& Petersson, 2003).

In Germany, approximately 7.5 million adults are considered functionally illiterate (Grotlüschen, \& Riekmann, 2011). According to the OECD, in Europe up to $40 \%$ of the native popula- tion are affected (Sweden: 8\%; Portugal: 40\%; OECD and Statistics Canada, 2000). Recent data indicate that in Germany, only a fraction of the functional illiterates attend adult literacy training courses (40.000 to 60.000 according to Döbert, \& Hubertus, 2000). Thus, there seems to be a need for the development of literacy education courses especially aimed at the adult population. The present paper describes such a program and presents first data on its effectiveness.

\section{Description of the Training Program “Alpha Plus”}

The training program “Alpha Plus” was developed in a joint effort of the Department of Psychology, University of Magdeburg, Germany, MediTECH Medizinelektronik, Region Hannover, Germany and the Bildungswerk der Niedersächsischen Wirtschaft (BNW), Osnabrück, Germany. Funding was kindly provided by the German Ministry of Education and Research (BM$\mathrm{BF})$.

The program is designed for adults who attended school but have severe and persisting problems with written language tasks in their everyday life. It is aimed at people whose mother tongue is German. The lack of reading and writing skills often leads to problems in getting and maintaining a job. The aim of the program is to teach reading and writing to functionally illiterate adults with the ultimate goal of integrating them into the labor market. This will open up new perspectives for participating in society and for gaining economic independence.

To achieve sustained success of the training and to ensure 
that the participants will engage in reading and writing in their everyday lives it is important to use training material that is relevant to the everyday life of the trainees. Thus, a general principle in literacy courses for adults should be an orientation on everyday life language tasks and on workplace literacy. Learning to read and write should enable participants to overcome their social isolation and lead to an increased assertiveness in situations involving written language tasks.

Reading and writing abilities of the participants will be on different levels at the beginning of the course. Thus, it is important to develop individualized learning agreements with each trainee. Furthermore, an assessment of the reading and writing skills of each participant is necessary at the beginning and during various stages of training for evaluation purposes.

The following standardized tests are proposed for reading and writing assessment in German speaking participants: Würzburger Leise Lese Probe (WLLP; Küspert \& Schneider, 1998), Salzburger Lese- und Rechtschreibtest (SLRT-II; Moll \& Landerl, 2010), Diagnostischer Rechtschreibtest für 1. Klassen, Diagnostischer Rechtschreibtest für 2. Klassen (DRT-1 and DRT-2; Müller, 2003a, 2003b), Hamburger Schreibprobe (HSP; May, 2001).

The training consists of several modules: 1) training of basic perceptual abilities with the BrainBoy ${ }^{\circledR} /$ Audio-Trainer AT-3000; 2) training of brain-hemisphere coordination in processing spoken and written language ("Lateraltrainer"); 3) training of phoneme discrimination ("Lautdiskriminationstrainer"); 4) training of reading and writing skills with pen and paper-based material; 5) use of the learning portal www.ich-will-lernen.de developed by the German Volkshochschulverband (VHS); 6) social activities such as cooking, shopping etc.; 7) three weeks internship at possible employers. The duration of the training course is eight months with daily classes between 8 am and 3 $\mathrm{pm}$. The modules are described in more detail below:

1) Training of basic perceptual abilities with the BrainBoy ${ }^{\circledR} /$ Audio Trainer AT-3000 (MediTECH, Region Hannover, Germany; http://www.meditech.de).

Research on dyslexia has identified a phonological deficit as a major cause of problems in the acquisition of reading (the phonological deficit hypothesis of dyslexia, see Snowling, 2000). However, different hypotheses exist that try to explain the origin of the phonological deficit. While the phonological deficit hypothesis is of a cognitive nature, other researchers try to explain dyslexia on a biological level. One such account, the "rapid auditory processing deficit hypothesis of dyslexia" (Tallal, Miller, \& Fitch, 1993; Tallal, 2004) proposes that children with language learning problems are specifically impaired in both their ability to discriminate between and to produce speech sounds that are characterized by brief, rapidly successive acoustic changes. An example for such stimuli are the brief formant transitions (40 ms) that precede the steady-state portion of the vowel, which is the sole differentiating feature between syllables such as /ba/ and /da/. Such perceptual problems may lead to inadequate formation of phoneme representations and, thus, may be the underlying (biological) cause of the phonological deficits described in dyslexia (on the cognitive level). This, in turn, leads to problems in mapping graphemes to phonemes when formal reading instruction begins at school. For example, Fischer and coworkers showed that $70 \%$ of 250 German dyslexic readers aged 7 - 22 years had inadequate auditory discrimination skills (Fischer \& Hartnegg, 2004). Training of auditory discrimination in dyslexic children resulted in an in- crease in auditory discrimination abilities and in better performance in reading and writing tests (Schäffler et al., 2004; see also Ptok, 2000; Tewes, Steffen, \& Warnke, 2003). Auditory processing deficits have also been shown in adult functional illiterates (Greenberg et al., 1997; Eme, 2011). Thus, the current training program includes a training of basic perceptual abilities with the BrainBoy ${ }^{\circledR} /$ Audio-Trainer A-T 3000 (BUPSystem) that is performed for 30 to 60 minutes daily. The following eight perceptual abilities are trained:

Temporal order judgment, visual ("Sehtakt"): Two short light flashes are presented on LEDs integrated on the left and right side of the BrainBoy ${ }^{\circledR}$ device. The subject has to decide which of the two light flashes occurred first. The time between the two flashes is shortened after correct and prolonged after wrong responses.

Temporal order judgment, auditory (“Hörtakt”): Two short tones are presented via headphones to the left and right ear, respectively. Subjects have to decide which of the two tones had been presented first (the left or the right one). The time between the two tones is shortened after correct and prolonged after wrong responses.

Auditory direction judgment ("Richtung”): “Click” sounds that model the timing differences between the two ears in a way that creates a sense of directionality are presented via headphones. Participants have to indicate whether the tone originnates from the left or from the right side. The level of difficulty changes adaptively.

Pitch discrimination (“Tonhöhe”): Two tones differing in pitch are presented via headphones. Subjects have to indicate whether the higher or the lower tone was presented first. The pitch difference between the two tones is changed adaptively.

Auditory-motor coordination ("Metronom"): Click-sounds are presented alternately to the left and to the right ear. Participants have to press a left or a right button according to the beat of the presented tones (left hand—left button, right hand—right button). If key-pressing is synchronized with the presented tones, the tempo of the beat increases.

Choice reaction task ("Reaktion”): A high and a low tone are presented in random succession to the left and to the right ear via headphones. Subjects have to press the button on the side of the BrainBoy ${ }^{\circledR}$-device corresponding to the presentation of the lower of the two tones. Response speed is emphasized in the instruction for this task.

Auditory frequency-pattern discrimination (“Tonfolge”): Three tones are presented. Subjects have to indicate the position of the tone that differs in pitch from the other two tones (first-middle: final tone). The duration of the tones and the interstimulusinterval are changed adaptively.

Auditory duration-pattern discrimination (“Tonlänge”): Three tones differing only in length are presented (one tone is double the length of the other two tones). Subjects have to indicate the position of the longer tone (first-middle-final tone). The duration of the tones and the inter-stimulus-interval are changed adaptively.

2) Training of the coordination of the two brain hemispheres in processing spoken and written language ("Lateraltrainer”).

Language processing is lateralized in the brain. In dyslexic readers, the processing of spoken and written language is less lateralized compared to normal readers (Shaywitz \& Shaywitz, 2008). Furthermore, it has been shown that a training focussing on phonological processing strategies increases left hemisphere activity in dyslexic readers (Shaywitz et al., 2004). Furthermore, 
dyslexic readers have problems with integrating the sound and the pictures of letters. This has been linked to an underactivation of the superior temporal cortex for the integration of letters and speech sounds in dyslexics (Blau et al., 2009). We assume that problems with lateralization in speech processing and in the neural integration of letters and speech sounds contribute to the problems in acquiring reading and writing skills that are prevalent in functional illiterates. The "Lateraltrainer" is used to overcome these problems. Headphones are used to present two different language streams to the left and to the right ear, respectively (the clients' voice and the voice of a model). The "ear of input" shifts every few seconds (e.g. first step: own voice is presented to the left ear, model voice is presented to the right ear; second step: own voice is presented to the right ear, model voice is presented to the left ear; third step: own voice is presented to the left ear, model voice is presented to the right ear and so forth). These constant changes of the ear of input should encourage integration processes between the two hemispheres of the brain.

Furthermore, the technique of synchronized speaking is used. The model voice of a teacher is presented over headphones and the participants are instructed to read aloud the same syllables or short words as the teacher. These words are presented via MS Office PowerPoint ${ }^{\circledR}$ slides. The synchronous reading of letters and speaking of words should foster the integration of letters and speech sounds. In addition, it conveys insights into the phonological structure of language. The training begins with the reading of syllables. Later, short words and short texts are used as reading material.

3) Training of phoneme discrimination ("Lautdiskriminationstrainer”).

The discrimination of similar sounding phonemes or consonants is trained with the "Lautdiskriminationstrainer". The learner hears via headphones short nonsense words that always begin with the letter "e" and end with the letter "i". The central letter is a consonant that changes from trial to trial (e.g. "ebi”, "eki”, “epi”). The learner has to type the heard middle letter on a computer keyboard. If the answer is incorrect, the same word is repeated up to three times.

The training with the "Lateraltrainer" and with the "Lautdiskriminationstrainer" was conducted for approximately one hour on a daily basis.

4) Training of reading and writing skills with pen and paperbased material.

We developed three modules of pen and paper exercises that were used in the class. In the first module, the letters are introduced (block letters). The training begins with single letters and syllables. When a participant is successful in working with the syllables, short words are introduced. Letter combinations that are common in German are used preferably. Later, somewhat more complex words are used. Importantly, the choice of words that are trained accounts for the relevance of the words in everyday life. Words that need to be read often (e.g. place names) are included in the training at the earliest possible stage. It is important to confirm that participants really read the words during training and not simply learn them by rote memorization.

The goal of the first module is that participants learn the correspondence of phonemes and graphemes. Furthermore, they should gain insights into the phonological structure of words/ language. The training in module one combines the written material with the "Lateraltrainer" and the "Lautdiskrimination- strainer".

Module two uses increasingly longer words and sentences. The participants begin to write short sentences by themselves. They are encouraged to bring texts that are very difficult to read for them. These are used as training material with the "Lateraltrainer”. Texts can include letters, newspaper articles, medical prescriptions, TV listings, bus or train schedules etc. By the use of such texts the participants can see and experience that reading helps them in everyday life. This should increase their motivation to learn to read and write. Apart from the texts chosen by the participants, text material that is used in this module focuses on everyday-life tasks (shopping, filling out standard forms, reading job offers etc.).

Participants should learn how to structure words at the morpheme level. This will help them to read longer words later on.

To help participants to recognize frequently occurring words quickly, each learner creates an individual notebook containing important words.

The module also contains an introduction to the composition of letters and instructions on how to use the internet for researching job offers (and how to read them).

The main aim of the third module is to consolidate and to automatize the reading and writing abilities of the participants. Furthermore, punctuation and the adequateness of the grammatical structures used in the composition of own texts are focused on.

Each participant develops her individual job application file with the help of the course teacher.

5) www.ich-will-lernen.de

The online learning platform www.ich-will-lernen.de (developed by the Deutsche Volkshochschul-Verband (DVV)) provides exercises to learn to read and write, to solve arithmetic problems and to manage personal financial affairs. It was used on an individual basis whenever a participant finished with the assigned task and had to wait for the other group members to complete an assignment. Furthermore, it was used by all group members in parallel for around two hours weekly.

6) Social activities.

Social activities like shopping in the supermarket, cooking, visiting the stadium of the local soccer team etc. were also part of the program.

7) Internship.

At the end of the course, all participants took part in an internship at local enterprises that lasted for three weeks. The main goal of the internship was to enhance the employability of the participants.

\section{Method}

The training program described in the preceding paragraph was implemented in two courses taking place in March-October 2009 and 2010, respectively. The courses were held by the Bildungswerk der Niedersächsischen Wirtschaft (BNW), Osnabrück, Germany, Monday to Friday from 8 am to $3 \mathrm{pm}$.

Participants. Most of the participants were referrals from the Maßarbeit Kreis Osnabrück KAöR (a state-run agency for the management of unemployment). All subjects participated voluntarily. Drop-out had no financial consequences for the participants (i.e. was not sanctioned by cutting social security benefits).

Course 2009. 18 subjects (one female, five left-handed) aged 27 to 58 years (mean age 40.7 years) with normal hearing and 
normal visual abilities participated in the training. There were no drop-outs. All participants indicated German as their mother tongue. They had attended school for four to 12 years. Two subjects had completed vocational training. At the time of the course all participants were unemployed.

Course 2010. 18 subjects (nine female, one left-handed) aged 25 to 54 years (mean age 44.9 years) with normal hearing and normal visual abilities participated in the training. There were eight additional drop-outs (one for medical reasons, one for unknown reasons, six accepted job offers). All participants indicated German as their mother tongue. They had attended school for eight to 12 years. None of the participants completed vocational training. At the time of the course all participants were unemployed.

Control group. 10 participants (three female, all right-handed, aged 29 - 67 years, mean age 42 years) of adult reading and writing education courses offered by a German adult education institution were tested for their reading and writing ability before and after attending adult literacy education courses for at least 10 months. A typical course consists of one or two classes a week that last for 90 minutes. Various teaching material and methods are employed in these courses.

Assessment instruments. Reading and writing abilities of the participants were assessed prior to and after the training with the Würzburger Leise Lese Probe (WLLP; Küspert \& Schneider, 1998), the Diagnostischer Rechtschreibtest für 1. Klassen (DRT-1; Müller, 2003a) and the Diagnostischer Rechtschreibtest für 2. Klassen (DRT-2; Müller, 2003b).

The WLLP measures (silent) reading speed and the ability to decode written words. 140 written words are shown one at a time. To the left of the word four pictures are presented. Subjects have to indicate the picture corresponding to the word. The test score comprises the number of correctly read words in five minutes.

Spelling abilities were assessed by the DRT-1 and DRT-2. These are commonly used tests for the assessment of spelling abilities in grade 1 and grade 2 school children in Germany. Different parallel test forms were used in the pre- and in the post-training assessment.

Non-verbal intelligence was assessed by using the Grundintelligenztest Skala 2 (CFT-20; Weiß, 1998), the German version of the culture fair intelligence test (CFT). A short form consisting of 4 subtests was used.

\section{Results}

The results of the pre- and post-training assessment of reading and writing skills of the two training groups are shown in Figures 1 and 2.

Course 2009. Average IQ as measured with the CFT was 83.8 (range: 71 to 96 ). Nine participants had an average IQ and nine participants had an IQ below average. Reading improved from 40.3 to 60.8 words read silently during a period of five minutes $\left(\mathrm{T}_{17}=3.96, p<.001\right)$. Spelling also improved reliably (DRT-1: 17.5 vs. 12.1 errors $\left(\mathrm{T}_{17}=4.42, p<.001\right)$, DRT-2: 23.7 vs 18.5 errors $\left.\left(\mathrm{T}_{17}=4.06, p<.001\right)\right)$.

Course 2010. Average IQ as measured with the CFT was 86.4 (range: 73 to 97). Ten participants had an average IQ and eight participants had an IQ below average. Reading improved from 51.1 to 65.6 words read silently during a period of five minutes $\left(\mathrm{T}_{17}=4.05, p<.001\right)$. Spelling also improved reliably (DRT-1: 12.8 vs. 7.7 errors ( $\mathrm{T}_{17}=4.85, p<.001$ ), DRT-2: 19

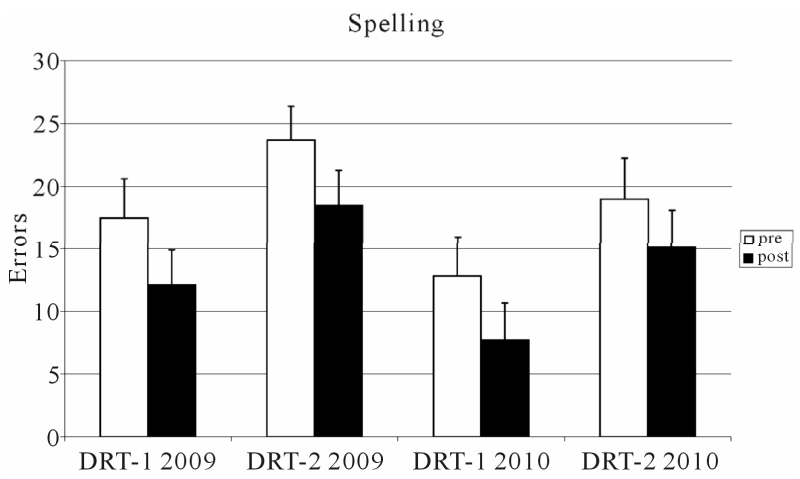

Figure 1.

Mean number of errors and standard error in the spelling tests DRT-1 and DRT-2 prior to (white bars) and after the training (black bars). Please note that different parallel forms of the tests were used in the pre- and post training assessment. It can be seen that participants showed significantly less spelling errors after the training.

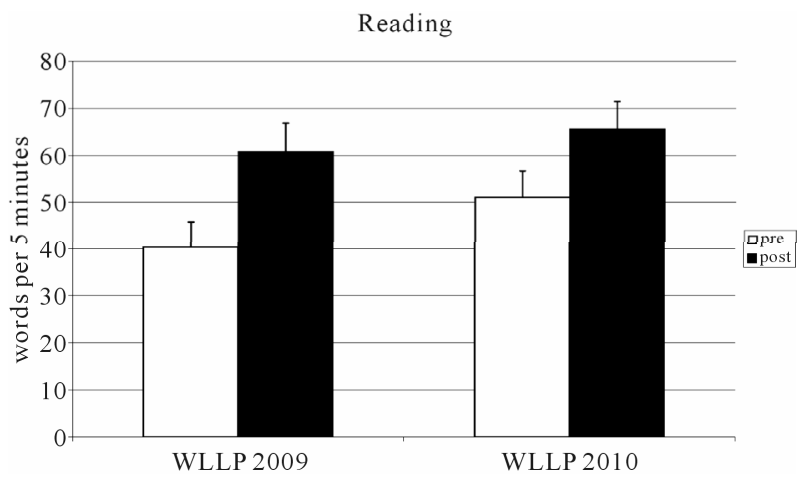

Figure 2.

Reading speed (number of words read correctly in five minutes) as assessed with the WLLP in the course taught in 2009 (left) and in the course taught in 2010 (right). Please note that in both courses, subjects read significantly faster after the training.

vs 15.1 errors $\left(\mathrm{T}_{17}=2.8, p<.02\right)$.

Six participants passed the forklift license examination, theoretical part. Six participants got a job immediately after the course finished.

Control group. Reading and writing did not improve signifycantly in the control group (WLLP: 50.3 vs. 53.9 words, T(9) = $1.17, p=.273$; DRT-1: 8.3 vs. 9.8 errors, $\mathrm{T}(9)=2.24, p=.052$ (note that after attending a course, participants made more spelling errors, albeit not reliably so); DRT-2: 25.4 vs. 22.8, $\mathrm{T}(9)=1.89, p=.096)$.

\section{Discussion}

The training program "Alpha Plus" serves to teach reading and writing to functionally illiterate German adults. It consists of several modules: 1) training of basic perceptual abilities with the BrainBoy ${ }^{\circledR} /$ Audio-Trainer AT-3000; 2) training of brainhemisphere coordination in processing spoken and written language (“Lateraltrainer”); 3) training of phoneme discrimination ("Lautdiskriminationstrainer"); 4) training of reading and writing skills with pen and paper-based material; 5) use of the learning portal www.ich-will-lernen.de developed by the German Volkshochschulverband (VHS); 6) social activities such as cooking, shopping etc.; 7) three weeks internship at possible 
employers. The participation in this course of eight months duration resulted in an improvement in reading and writing skills of the attending adults. Spelling accuracy as well as reading speed and accuracy improved significantly. In contrast, functional illiterates participating in traditional adult education courses that take place once or twice a week and use various teaching methods did not show reliable improvements in reading or writing. Thus, we conclude that the program "Alpha Plus" is an effective training program for teaching reading and writing competencies to functionally illiterate adults.

We observed several important changes of participants' attitudes toward their reading and writing problems during the training. At the beginning, all participants were reluctant to talk to other people about the nature of the course they were attending. The experience that other adults have similar problems with reading and writing and that it is possible to do something to overcome these problems has, throughout the course, lead to a more active handling of the problem. For example, the participants took part in the "open day" of the BNW (about five months after the course). They made a poster on which most of them were pictured and listed by name. They desired to inform other functional illiterates about the opportunities that are opened up by attending a reading and writing training course in adulthood.

Prior to and at the end of the course, participants took part in a medical examination. For all participants, weight loss was observed. Health-related issues (such as a healthy diet) were discussed frequently during the course and on several occasions, lunch was prepared together. The weight loss might be attributable thereto.

The present study has several shortcomings. First, we did not include a control group that received the same amount of training as the training group. This was done mainly for reasons of practicability. However, we included a control group receiving training that is typical for adult functional illiterates in Germany (at least for those few who receive some kind of training). Second, the design of the present study does not allow conclusions with respect to the contribution of the single modules to the overall success of the training. The training of basic perceptual abilities and the "Lateraltrainer" have been shown to be effective in the training of reading to children with dyslexia (Tewes, Steffen, \& Warnke, 2003). To date, we have no information about the effectiveness of the other single modules that were included in the current program. Further research is required to investigate which of the employed training methods are essential for the training success.

\section{Acknowledgements}

The research reported herein was supported by a grant from the German Ministry of Education and Research (Bundesministerium für Bildung und Forschung, BMBF) assigned to JR (grant no. 01AB074401). The opinions that may be stated in this paper are those of the authors.

The authors declare that they have no personal financial interest in the developed training program.

\section{REFERENCES}

Baydar, N., Brooks-Gunn, J., \& Furstenberg, F. F. (1993). Early warning signs of functional illiteracy: Predictors in childhood and adolescence. Child Development, 64, 815-829. doi:10.2307/1131220

Blau, V., van Attefeldt, N., Ekkebus, M., Goebel, R., \& Blomert, L.
(2009). Reduced neural integration of letters and speech sounds links phonological and reading deficits in adult dyslexia. Current Biology, 19, 503-508. doi:10.1016/j.cub.2009.01.065

Döbert, M., \& Hubertus, P. (2000). Reading is their problem: Functional illiteracy in Germany (Ihr kreuz ist die schrift: Analphabetismus und alphabetisierung in Deutschland). URL (last checked 20 April 2012).

http://www.alphabetisierung.de/fileadmin/files/Dateien/Downloads_ Texte/IhrKreuz-gesamt.pdf

Eme, E. (2011). Cognitive and psycholinguistic skills of adults who are functionally illiterate: Current state of research and implications for adult education. Applied Cognitive Psychology, 53, 752-763.

Fischer, B., \& Hartnegg, K. (2004). On the development of low-level auditory discrimination and deficits in dyslexia. Dyslexia, 10, 105118. doi:10.1002/dys.268

Greenberg, D., Ehri, L. C., \& Perin, D. (1997). Are word reading processes the same or different in adult literacy students and third-fifth graders matched for reading level? Journal of Educational Psychology, 89, 262-275. doi:10.1037/0022-0663.89.2.262

Grotlüschen, A., \& Riekmann, W. (2011). Leo level one-Studie, presseheft. URL (last checked 23 January 2012). http://blogs.epb.uni-hamburg.de/leo/

Kirsch, I. S., Jungeblut, A., Jenkins, L., \& Kolstad, A. (1993). Adult literacy in America: A first look at the results of the national adult literacy survey. Washington DC: US Department of Education, National Center for Education Statistics.

Küspert, P., \& Schneider, W. (1998). Würzburg silent reading test (Würzburger leise lese probe). Göttingen, LS: Hogrefe.

May, P. (2001). Hamburger writing test (Hamburger schreibprobe). Hamburg: Vpm Lernbuch-Verlag.

Moll, K., \& Landerl, K. (2010). Reading and writing test (SLRT-II. Leseund rechtschreibtest). Bern: Huber.

Müller, R. (2003a). Diagnostic writing test for 1st grade students (Diagnostischer rechtschreibtest für 1. klassen). Weinheim, BW: BeltzPVU.

Müller, R. (2003b). Diagnostic writing test for 2nd grade students (Diagnostischer rechtschreibtest für 2. klassen) (4th ed.). Weinheim, BW: BeltzPVU.

OECD and Statistics Canada (2000). Literacy in the information age: Final report of the International Adult Literacy Survey. Paris and Ottawa: OECD Publishing.

Ptok, M. (2000). Auditory processing deficits and dyslexia (Auditive verarbeitungs- und wahrnehmungsstörungen und legasthenie). Hessisches Ärzteblatt, 2, 52-54.

Reis, A., Guerreiro, M., \& Petersson, K. M. (2003). A sociodemographic and neuropsychological characterization of an illiterate population. Applied Neuropsychology, 10, 191-204. doi:10.1207/s15324826an1004_1

Schäffler, T., Sonntag, J., Hartnegg, K., \& Fischer, B. (2004). The effect of practice on low-lewel auditory discrimination, phonological skills and spelling in dyslexia. Dyslexia, 10, 119-130. doi:10.1002/dys.267

Shaywitz, B., Shaywitz, S., Blachman, B., Pugh, K., Fulbright, R., Skudlarski, P., Mencl, W. E., Constable, R. T., Holahan, J. M., Marchione, K. E., Fletcher, J. M., Lyon, G. R., \& Gore, J. C. (2004). Development of the left occipital systems for skilled reading in children after a phonologically-based intervention. Biological Psychiatry, 55, 926-933. doi:10.1016/j.biopsych.2003.12.019

Shaywitz, S. E., \& Shaywitz, B. A. (2008). Paying attention to reading: The neurobiology of reading and dyslexia. Development and Psychopathology, 20, 1329-1349. doi:10.1017/S0954579408000631

Snowling, M. J. (2000). Dyslexia (2nd ed.). Oxford: Blackwell.

Tallal, P. (2004). Improving language and literacy is a matter of time. Nature Reviews Neuroscience, 5, 721-728. doi:10.1038/nrn1499

Tewes, U., Steffen, U., \& Warnke, F. (2003). Automatization deficits as a cause of learning deficits (Automatisierungsstörungen als ursache von lernproblemen). Forum Logopädie, 1, 24-30.

Weiß, R. H. (1998). German adaptation of the culture fair intelligence test CFT-20 (Grundintelligenztest Skala 2 (CFT 20) mit wortschatztest (WS) und zahlenfolgentest (ZF)). Göttingen, LS: Hogrefe. 